\title{
A PARADIPLOMACIA COMO FORMA DE INSERÇÃO INTERNACIONAL DE UNIDADES \\ SUBNACIONAIS
}

\author{
Álvaro Chagas Castelo Branco*
}

\section{Introdução}

As relações internacionais sempre se fizeram presentes nas civilizações, principalmente a partir da formação dos Estados soberanos. Por sua vez, é consenso na doutrina do Direito Internacional Público que o tratado é a fonte escrita mais importante desse ramo publicístico do direito, não só em razão da sua larga utilização, como também devido à importância das matérias que por eles são regulamentadas.

Desde as épocas mais remotas, foram os princípios consuetudinários do livre convencimento, da boa-fé dos contraentes e da norma do pacta sunt servanda, que regeram a celebração dos tratados. No entanto, a partir de 1949, já no âmbito das Nações Unidas, o desejo de uma codificação das regras sobre o Direito dos Tratados começou a se materializar. Finalmente, no ano de 1969, foi finalizado o texto da Convenção de Viena sobre o Direito dos Tratados, sendo que apenas no dia 27 de janeiro de 1980, após o depósito de trinta e cinco ratificações, tal instrumento normativo entrou internacionalmente em vigor.

No início da regulamentação dos tratados, somente os Estados soberanos eram considerados pessoas jurídicas de direito público externo. No entanto, o ordenamento jurídico internacional viu surgir, notadamente a partir das primeiras décadas do século $\mathrm{XX}$, uma nova modalidade de sujeito de direitos e obrigações internacionais: as organizações internacionais.

Questão bastante atual discutida no Direito Internacional, objeto do presente artigo, consiste na possibilidade de entes não centrais celebrarem tratados $\mathrm{e}$ atos internacionais, em particular, estados membros e municípios de um Estado Federal. A doutrina mais tradicional entende que à exceção das organizações internacionais, apenas os Estados soberanos, em razão de sua qualidade de sujeito do Direito das Gentes, possuem capacidade para celebrar tratados, típica manifestação de vontade de sua personalidade jurídica internacional. Algumas constituições de estados federados excluem totalmente

\footnotetext{
* Advogado da União. Professor da FAJS do UniCEUB. Especialista em Direito pela Universidade Gama Filho. Mestrando em Direito das Relações Internacionais, pelo UniCEUB. E-mail: alvaro.castelobranco@uniceub.br.
} 
qualquer possibilidade de celebração de atos internacionais por parte dos entes federados. Outras reconhecem expressamente o jus tractuum das entidades infraestatais.

Verifica-se, na verdade, que todo o modelo de celebração de tratados, tendo por base a capacidade exclusiva dos entes dotados de personalidade jurídica internacional foi levado a cabo e desenvolvido a partir de um modelo de federalismo tradicional e assimétrico, com a concentração de vários poderes e prerrogativas nas mãos de um ente central.

Tal modelo tende a não atender, de forma satisfatória, aos anseios e interesses dos entes não centrais na condução de suas atividades, haja vista a intensificação das relações internacionais, substancialmente facilitadas com todos os avanços tecnológicos da humanidade e com o processo de globalização.

No caso do ordenamento jurídico brasileiro, especificamente, apesar de a Constituição da República de 1988 ter contribuído para a consolidação do processo de democratização do país, sob diversos ângulos, não se encontrou um equilíbrio nas relações federativas, notadamente no que diz respeito às relações internacionais, tanto que a condução das relações externas é concentrada no ente central, pouco restando para os estados e municípios.

Nada obstante, apesar de não haver um modelo institucionalizado de atuação internacional dos entes não centrais no ordenamento jurídico pátrio, verifica-se que o processo de democratização do país, iniciado em 1982 com a eleição dos governadores, deu início aos primeiros casos do que poderia se chamar "política externa federativa" A partir daí, até mesmo em razão dos problemas estruturais que propiciam o desenvolvimento da paradiplomacia no Brasil, a atuação externa dos entes subnacionais vem crescendo a cada dia.

\section{A capacidade de celebrar tratados}

De acordo com a Convenção de Viena sobre o Direito dos Tratados, "tratado significa um acordo internacional concluído por escrito entre Estados e regido pelo Direito Internacional, quer conste de um instrumento único, quer de dois ou mais instrumentos conexos, qualquer que seja sua denominação específica".

A maioria dos autores prefere o conceito de tratado positivado na Convenção de Viena, e, ainda assim, aqueles que procuram conceituação diversa, não se distanciam muito da 
definição dada pela Convenção de Viena. Dentre os autores clássicos, Von Liszt o conceitua como o acordo entre dois ou mais Estados sobre direito próprios de soberania. ${ }^{1}$

Alain Pellet considera que "o tratado designa qualquer acordo concluído entre dois ou mais sujeitos de direito internacional, destinado a produzir efeitos de direito e regulado pelo direito internacional.",2 Para Francisco Rezek, "é todo acordo formal concluído entre sujeitos de direito internacional público, e destinado a produzir efeitos jurídicos." ${ }^{, 3} \mathrm{Na}$ definação de Clóvis Beviláqua, "tratado internacional é um ato jurídico, em que dois ou mais Estados concordam sobre a criação, modificação ou extinção de algum direito", completando que a "definição acima exposta abrange todos os atos jurídicos bilaterais ou multilaterais do direito público internacional, que, realmente, podem ser designados pela denominação geral de tratados, mas que recebem, na prática e nos livros de doutrina, qualificações diversas". 4

Em 1992, o Presidente da República à época, Itamar Franco, enviou mensagem ao Congresso Nacional para que a Convenção de Viena sobre o Direito dos Tratados fosse submetida à aprovação. Após rápida apreciação, transformou-se no projeto de Decreto Legislativo n. ${ }^{\circ}$ 214/1992. No dia 22 de fevereiro de 1995, foi aberto à apresentação de emendas de plenário. No entanto, mesmo sem a devida aprovação pelo Congresso Nacional e sem a ratificação pelo Presidente da República, a Convenção de Viena é considerada principal fonte, como costume internacional, para as negociações do Ministério das Relações Exteriores. $^{5}$

Enquanto os Estados eram considerados como os únicos sujeitos diretos deste direito, os tratados não podiam ser atos interestatais. No entanto, o ordenamento jurídico internacional viu surgir, notadamente a partir das primeiras décadas do século XX, uma nova modalidade de sujeito de direitos e obrigações internacionais: as organizações internacionais.

Virally, em seu conceito de tratado, já estendia às organizações internacionais a capacidade para celebrar tratados, ao afirmar que tratado é qualquer acordo internacional

\footnotetext{
${ }^{1}$ VON LISZT, Franz. Derecho internacional público. Barcelona: Gustavo, 1929, p. 224.

2 PELLET, Alain; DAILLIER, Patrick; DINH, Nguyen Quoc. Direito internacional público. 2. ed. Lisboa: Fundação Calouste Gulbenkian, 2003. p. 120.

${ }^{3}$ REZEK, José Francisco. Direito dos tratados. Rio de Janeiro: Forense, 1984. p. 21.

${ }^{4}$ BEVILÁQUA, Clóvis. Direito público internacional. 2. ed. Rio de Janeiro: F. Bastos, 1939. t. 2. p. 13.

${ }^{5}$ Atualmente o projeto de Decreto Legislativo n. ${ }^{\circ}$ 214/1992 encontra-se ainda na Câmara dos Deputados, e sua última movimentação foi Leitura e publicação dos pareceres da CCJR e CRE, ao projeto e a emenda de Plenário. BRASIL. Diário da Câmara dos Deputados. Brasília, 08 dez. 1995. p. 3386. col. 01.
} 
celebrado por dois os mais Estados ou outras pessoas internacionais e que está regido pelo Direito Internacional. ${ }^{6}$

Atualmente, está assentado que, além dos Estados soberanos, as organizações possuem personalidade internacional e, portanto, capacidade para celebrar tratados, mas essa capacidade possui limites, nos próprios propósitos e funções dessas organizações, previstas em seus estatutos ou nas decisões de seus órgãos.

Da sua própria definição, portanto, bem como da evolução do fenômeno convencional internacional, depreende-se que os tratados são o alicerce basilar que regulamentarão a maioria das relações entre os organismos internacionais.

\section{0 processo de formação dos tratados no ordenamento jurídico brasileiro}

Desde os primeiros passos do Brasil republicano, a sistemática de incorporação dos tratados e do Direito Internacional ao ordenamento jurídico interno sofreu fortes influências dos modelos americano e francês, os quais previam a necessidade do consentimento parlamentar como condição para a validade interna e internacional dos tratados.

Atualmente, o processo de formação dos tratados e sua entrada em vigor no ordenamento jurídico brasileiro segue a sistemática prevista na Convenção de Viena sobre o Direito dos Tratados, de 1969.

Por se tratar de atos solenes, o seu aperfeiçoamento requer a observância de formalidades distintas e sucessivas. São quatro as fases de incorporação de um tratado: a) negociações diplomáticas preliminares; b) assinatura ou adoção, pelo Poder Executivo; c) aprovação parlamentar; d) ratificação ou adesão do texto normativo, seguida da troca ou depósito dos instrumentos convencionais. No Brasil, após a sua ratificação, o tratado deverá ser promulgado por Decreto do Presidente da República, e publicado no Diário Oficial da União, para que possam ter aplicabilidade e executoriedade internas. ${ }^{7}$

\footnotetext{
${ }^{6}$ SORENSEN, Max. Manual de derecho internacional público. México: Fondo de Cultura Económica, 1998. p. 155.

${ }^{7}$ Para o Supremo Tribunal Federal, os tratados somente adquirem vigência na ordem interna após a promulgação e publicação de seu texto, pela via do decreto de execução presidencial que o coloca em vigor. BRASIL. Supremo Tribunal Federal. Carta Rogatória n. ${ }^{\circ}$ 8.279, da República Argentina, de 04 de maio de 1998. Rel. Min. Celso de Mello. Julgada em 17 jun. 1998. Diário da Justiça da União, Brasília, 10 ago. 2000. p. 34.
} 
É interessante ressaltar que, antes mesmo da ratificação, todos os direitos e obrigações expressos no tratado ficam restritos às relações mútuas dos contratantes, não tendo se incorporado, efetivamente, no ordenamento jurídico interno desses mesmos Estados.

Questão bastante atual discutida no Direito Internacional consiste na possibilidade de entes não centrais celebrarem tratados e atos internacionais, em particular, estados membros e municípios de um Estado Federal. A doutrina mais tradicional entende que, à exceção das organizações internacionais, apenas os Estados soberanos, em razão de sua qualidade de sujeito do Direito das Gentes, possuem capacidade para celebrar tratados, típica manifestação de vontade de sua personalidade jurídica internacional.

De fato, sustenta tal corrente que o direito de ajustar tratados e convenções deriva do direito de soberania, vez que todo Estado soberano possui capacidade para contratar, ou seja, para adquirir direitos e contrair obrigações por meio de tratados.

José Francisco Rezek assevera que apenas as pessoas jurídicas de direito internacional público - os Estados soberanos e as organizações internacionais - são sujeitos de direito internacional. No entanto, o mesmo autor faz importante ressalva no sentido de não se tratar aí de uma "verdade eterna", senão uma dedução segura daquilo que nos mostra a cena internacional contemporânea. ${ }^{8}$

Para Valério de Oliveira Mazzuoli, como ato jurídico internacional, os tratados só podem ser concluídos por entes capazes de assumir direitos e obrigações no âmbito externo, no caso, Estados soberanos e organizações internacionais. Mais adiante, deixa consignado que quanto aos Estados Federados, temos duas situações: aquela em que a União Federal reconhece a estes Estados o poder de celebrar tratados, e aquela outra em que a Constituição nada diz a respeito ou mesmo nega a existência de tal possibilidade. ${ }^{9}$

A Conferência de Viena rejeitou o artigo $5^{\circ}, \S 2^{\circ}$, do projeto elaborado pela Comissão de Direito Internacional, assim pretendido: "Os Estados membros de uma união federal podem ter capacidade para concluir tratados se esta capacidade for admitida pela constituição federal e estiver nos limites indicados pela dita constituição."

Releva dizer que a rejeição de tal dispositivo do corpo da Convenção de Viena sobre Direito dos Tratados não significa, necessariamente, que as entidades federadas não tenham o direito de celebrar tratados. Na realidade, a Conferência somente entendeu sublinhar o caráter interno do problema.

\footnotetext{
${ }^{8}$ REZEK, José Francisco. Direito internacional público. 9. ed. São Paulo: Saraiva, 2002. p. 145.

${ }^{9}$ MAZZUOLI, Valério de Oliveira. Tratados internacionais. 2. ed. São Paulo: J. Oliveira, 2004. p. 43-44. 
Interessante ressaltar também, que quando a Convenção de Viena Sobre Direito Dos Tratados Entre Estados e Organizações Internacionais ou Entre Organizações Internacionais, de 1986, em seu artigo $3^{\circ}$, faz referência a novos sujeitos de direito internacional, distintos dos sujeitos clássicos, uma vez que o texto remete a outros sujeitos de direito internacional. Ao contrário da Convenção de Viena sobre Direito dos Tratados, de 1969, ele não está tratando de organizações internacionais, mas de casos não previstos, como, por exemplo, as organizações supranacionais, alguns entes federados como capacidade de celebrar tratados.

Nesse sentido, Hildebrando Accioly afirma que quanto às unidades federadas componentes dos Estados compostos, a capacidade de celebrar tratados depende da forma ou da natureza do Estado composto, ou, antes, do grau de soberania conservada pelas unidades. A capacidade dos Estados semi-soberanos ou não autônomos depende da convenção que os prende aos respectivos Estados protetores ou administradores, ou da autorização recebida do Estado a que se achem subordinados. ${ }^{10}$

Celso D. Albuquerque Mello entende que os Estados federados podem ter também o direito de celebrar tratados, bastando apenas que o direito interno preveja, o que é raro no cenário mundial. ${ }^{11}$

Para Alain Pellet, a possibilidade da participação de entes não centrais em atos internacionais deve ser analisada sob um duplo enfoque: o da capacidade da entidade celebrar o tratado, e o da imputação do tratado a um tal sujeito. Sustenta o mestre francês:

No que respeita ao primeiro ponto, o direito internacional remete para o direito interno: uma instituição descentralizada pode concluir um tratado se esta capacidade lhe for reconhecida pelo direito constitucional do Estado de que depende, entendendo-se que os outros Estados nunca serão obrigados a concluir um tratado com uma tal entidade mas são livres de o fazer.

A questão da imputação do tratado concluído por uma entidade descentralizada com um Estado estrangeiro é inteiramente diferente: a responsabilidade internacional do Estado de que depende a entidade cocontratante encontrar-se-ia comprometida em caso do não respeito do compromisso, salvo se esta última tivesse manifestamente excedido as competências que lhe são reconhecidas em direito interno. ${ }^{12}$

\footnotetext{
${ }^{10}$ ACCIOLY, Hildebrando. Tratado de direito internacional público, v. 1. Rio de Janeiro: Ministério das Relações Exteriores, 1956, p. 560-561.

${ }^{11}$ MELO, Celso D. de Albuquerque. Curso de direito internacional público. v. 1, 13. ed. Rio de Janeiro: Renovar, 2001,p. 202.

12 PELET, Alain; DAILliER, Patrick; DINH, Nguyen Quoc. Direito internacional público. 2. ed. Lisboa: Fundação Calouste Gulbenkain, 2003. p. 193.
} 
A possibilidade de Estados despidos de personalidade jurídica internacional celebrarem tratados foi expressamente reconhecida pela Convenção das Nações Unidas sobre o Direito do Mar (Montego Bay, 10 de dezembro de 1982), ao prever no artigo 305, inciso 1, alínea "d", que a Convenção está aberta à assinatura de "todos os Estados autônomos associados que, de conformidade com os seus respectivos instrumentos de associação, tenham competência sobre as matérias regidas pela presente convenção, incluindo a de concluir tratados em relação a essas matérias."

Algumas constituições de estados federados excluem totalmente qualquer possibilidade de celebração de atos internacionais por parte dos entes federados, como a da Venezuela $^{13}$. Outras, como a da Suíça, a da Argentina e a da extinta União Soviética reconhecem expressamente o jus tractuum das entidades infraestatais.

No ordenamento jurídico brasileiro, especificamente, o art. 21, inciso I, da Constituição da República prevê: “Art. 21. Compete à União: I - manter relações com Estados estrangeiros e participar de organizações internacionais;"

Fazendo novamente remissão a Celso D. Albuquerque Mello, ao tratar da possibilidade de entes não centrais firmarem acordos internacionais no ordenamento pátrio, temos que:

O Direito Interno (Constituição) pode dar aos estados federados este direito, como ocorre na Suíça, na Alemanha Ocidental e na URSS. O governo federal no Brasil não será responsável se um Estado membro da federação concluir um acordo sem que ouvido o Poder Executivo Federal e nem seja aprovado pelo Senado. Os estados da federação norte-americana também podem concluir acordos, pelo menos é o que estabelece a Constituição, mas na prática jamais o fizeram para não violar [o] 'treaty-making power' do governo federal. ${ }^{14}$

Por sua vez, o artigo 52, inciso V, da Constituição da República dispõe:

Art. 52. Compete privativamente ao Senado Federal:

$[\ldots]$

V - autorizar operações externas de natureza financeira, de interesse da União, dos Estados, do Distrito Federal, dos Territórios e dos Municípios;

\footnotetext{
${ }^{13}$ Artículo 236. Son atribuciones y obligaciones del Presidente o Presidenta de la República:

[...]

4. Dirigir las relaciones exteriores de la República y celebrar y ratificar los tratados, convenios o acuerdos internacionales.

${ }^{14}$ MELO, Celso D. de Albuquerque. Curso de direito internacional público, 13. ed, v. 1. Rio de Janeiro: Renovar, 2001, p. 203.
} 
Com base no dispositivo constitucional acima transcrito, e assumindo uma postura mais arrojada, Roberto Luiz Silva defende que os entes não centrais brasileiros têm capacidades para celebrar tratados, da seguinte forma:

No Brasil, os Estados-membros, o Distrito Federal e os Municípios podem celebrar tratados de financiamento, desde que tenham aval do Senado Federal. Deve-se salientar que isso não ocorre em todos os Estados federados, pois a Lei Federal alemã concede às suas unidades federadas uma capacidade contratual bem resumida em termos de relações internacionais, enquanto nos EUA, por exemplo, há uma série de restrições constitucionais aos poderes dos Estados-membros, como se observa no artigo I, seção $10 .^{15}$

Nada obstante o entendimento acima defendido, tem-se que ressaltar que tais acordos de cunho financeiro, embora possam ser celebrados e revestidos sob a forma técnica de tratados, não podem ser interpretados e entendidos como tal, haja vista a falta de identidade jurídica dos institutos.

Em verdade, chega-se à conclusão de que todo o modelo de celebração de tratados, tendo por base a capacidade exclusiva dos entes dotados de personalidade jurídica internacional (Estados soberanos e organizações internacionais) foi levado a cabo e desenvolvido a partir um modelo de federalismo tradicional e assimétrico, com a concentração de vários poderes e prerrogativas nas mãos de um ente central.

Vislumbra-se, também, que tal modelo tende a não atender satisfatoriamente aos anseios e interesses dos entes não centrais na condução de suas atividades, haja vista a intensificação das relações internacionais, substancialmente facilitadas com todos os avanços tecnológicos da humanidade e com o processo de globalização.

A palavra "globalização" é relativamente recente no vocabulário econômico, político e jurídico e, a despeito disso, não envolve conteúdos unívocos. No discurso para retratar essa realidade, concorrem com ela os termos "mundialização" e, com menos freqüência, "internacionalização". No nível acadêmico, afirma Roland Robertson, o termo globalização certamente não era reconhecido como um conceito significativo, independentemente do seu difuso e intermitente uso anterior, até o início ou meados dos anos $80 .^{16}$

Com efeito, hoje já se discute a criação e desenvolvimento de uma espécie de "Direito Internacional Regional", voltado precipuamente para o atingimento dos interesses de

\footnotetext{
${ }^{15}$ SILVA, Roberto Luiz. Direito internacional público. 2. ed. Belo Horizonte: Del Rey, 2005. p. 46.

${ }^{16}$ ROBERTSON, Roland. Globalização: teoria social e cultural global. Petrópolis: Vozes, 2000. p. 23.
} 
entes não centrais em diversos setores, sem a necessidade da participação direta e às vezes burocrática de um ente central na conclusão dos negócios.

\section{$4 \mathrm{O}$ surgimento da paradiplomacia}

Nas últimas décadas o ordenamento jurídico mundial viveu um progressivo processo de intensificação das relações internacionais, criado e desenvolvido a partir de um novo cenário, que vem mudando as tendências de integração e interdependência internacionais. Nesse cenário, cresce com inegável força, a atuação internacional dos novos atores subnacionais.

Pode-se afirmar, forte em Tatiana Lacerda Prazeres, que ao se tratar da paradiplomacia, especificamente dos entes não centrais, deveria ser utilizada, de forma mais técnica a expressão "subestatal" e não "subnacional", respeitando a distinção entre Estado e nação. Mas assim como a renomada autora, para adotar a expressão que já se encontra consagrada na literatura específica, "subnacional" será o termo com freqüência utilizado no presente trabalho, feitas estas necessárias ressalvas. ${ }^{17}$

O declínio da antiga ordem internacional, que tradicionalmente esteve articulada ao redor do conceito da divisão do mundo em Estados-Nações plenamente soberanos, foi causado, sobretudo, pelas transformações conceituais que originaram a globalização. Os tratados de livre comércio, por exemplo, têm produzido um impacto regional diferenciado que necessita de estratégias próprias para a sua compreensão.

As alterações nos conceitos de fronteiras, causados pela abertura dos mercados, os incessantes fluxos migratórios mundiais, bem como a desconcentração, descentralização e regionalização do próprio Poder Público, acabaram por abrir um novo espaço nas relações internacionais, abalizado na própria concepção de democracia, e que reflete na intensificação da participação política e no desenvolvimento de adaptações e soluções para as especificidades dos atores não estatais.

De fato, com o processo de regionalização do Direito das Relações Internacionais, e diante da insuficiência das respostas dadas pela tradicional doutrina internacionalista, os defensores da paradiplomacia, que até o início dos anos 1980, era utilizada de forma casual e despretensiosa, passaram a defender a existência de novos atores no cenário das relações

\footnotetext{
${ }^{17}$ PRAZERES, Tatiana Lacerda. Por uma atuação constitucionalmente viável das unidades federadas brasileira. In: VIGEVANI, Tullo (Org.). A dimensão subnacional e as reações internacionais. São Paulo: Unesp, 2004. p. 283.
} 
internacionais, os entes subnacionais. Nesse contexto, James Rosenau já sugeria, à época, a existência de dois "mundos" na política internacional, compostos, respectivamente, pelos atores estatais e pelos atores não-estatais. ${ }^{18}$

Como se trata de um fenômeno relativamente recente em escala global, o estudo da participação dos entes não centrais nas relações internacionais é ainda incipiente, tanto na doutrina e meios acadêmicos nacionais, quanto internacionais. Nesse sentido, André Lecours assevera que "a atividade internacional dos governos regionais, ou paradiplomacia, como tem sido chamada, tem sido o enfoque de uma modesta, mas crescente literatura, que detalha vários casos e busca descobrir um significado para o fenômeno." 19

Damir Grubisa, professor da University Ivanic Grad, na Croácia, afirma que um importante marco para o estudo da paradiplomacia foi um seminário levado a cabo em Bilbao, Espanha, no ano de 1997, que reuniu os maiores estudiosos do assunto à época. De acordo com o autor, o resultado do evento, materializado em uma obra que reuniu diversos artigos, foi o desafio inicial de se entender a paradiplomacia. ${ }^{20}$

José Vicente da Silva Lessa, em um dos pioneiros estudos dedicados ao tema no ordenamento jurídico brasileiro, ressalta que a expressão paradiplomacia foi trazida ao debate acadêmico pelo basco Panayotis Soldatos, para designar a atividade diplomática desenvolvida entre entidades políticas não centrais situadas em diferentes Estados. O eminente doutrinador cita o canadense Ivo Duchacek, que introduziu uma distinção entre microdiplomacia regional transfronteiriça, microdiplomacia transregional e a paradiplomacia global, significando, respectivamente, contatos entre unidades não centrais fronteiriças localizadas em diferentes Estados, contatos entre unidades não centrais sem fronteiras comuns, mas cujos Estados nacionais são limítrofes, e contatos políticos entre unidades pertencentes a Estados distantes, que estabelecem ligações não apenas entre centros comerciais, industriais e culturais em

\footnotetext{
${ }^{18}$ ROSENAU, James. Patterned chaos in global life: structure and process in the two worlds of world politics. International Political Science Review, [S.1.], n. 9, p. 327, 1988.

19 "The international activity of regional governments, or 'paradiplomacy' as it has been termed, has been the focus of a modest but growing literature that details various cases and seeks to make sense of the phenomenon." ALDECO; KEATING, 1999; PALARD, 1999; BERNIER, 1994; MICHELMANN; SOLDATOS, 1990; DUCHACEK; LATOUCHE; Stevenson, 1988 apud LECOURS, André. Paradiplomacy: reflections on the foreign policy and international relations of regions. International Negotiation. [S.1.], n. 7, p. 92, 2002.

${ }^{20}$ GRUBISA, Damir. Paradiplomacy in action: the foreign relations of subnational governments. London: Mediterranean Politics, 1999. p. 144.
} 
outros continentes, mas também com os vários ramos ou agências de governos nacionais estrangeiros. $^{21}$

A classificação mais aceita de paradiplomacia é dada por Noé Cornago Prieto, para quem

\begin{abstract}
A paradiplomacia pode ser definida como o envolvimento de governo subnacional nas relações internacionais, por meio do estabelecimento de contatos, formais e informais, permanentes ou provisórios ('ad hoc'), com entidades estrangeiras públicas ou privadas, objetivando promover resultados socioeconômicos ou políticos, bem como qualquer outra dimensão externa de sua própria competência constitucional. Embora bastante contestado, o conceito de paradiplomacia não impossibilita a existência de outras formas de participação subnacional no processo da política externa, mais diretamente ligado ao departamento de relações exteriores de governos centrais, como a assim chamada diplomacia federativa, tampouco impede o papel cada vez maior dos governos subnacionais nas estruturas de multicamadas para a governança regional ou mundial. $^{22}$
\end{abstract}

\title{
5 Experiências paradiplomáticas no Brasil
}

A possibilidade da celebração de tratados por parte dos estados membros de um estado composto ou federado está baseada, sobretudo, na experiência histórica de cada país. Não se pode pretender estabelecer uma norma comum, que sirva como modelo a que todos os demais Estados federados devam se ajustar. Em alguns países a unidade nacional e a integração regional podem ser compreendidos de uma maneira tal que não haveria como se perceber o mínimo risco de um processo de desintegração, pela via do exercício da faculdade que se tem estudado. Em outros, a dificuldade para se conseguir a integração dentro da sua diversidade político-territorial talvez seja um elemento que dificulte uma "reforma" que possa abrir a possibilidade dos estados membros poderem celebrar tratados.

Pode-se afirmar, com respaldo em Gilberto Marcos Antônio Rodrigues, que o processo de democratização do país, iniciado em 1982, com a eleição direta dos governadores, deu início aos primeiros casos do que poderia se chamar de "política externa federativa". Leonel Brizola, então governador do estado do Rio de Janeiro, instituiu o primeiro órgão de articulação internacional de um ente federal brasileiro. Outro importante

\footnotetext{
${ }^{21}$ LESSA, José Vicente da Silva. A paradiplomacia e os aspectos legais dos compromissos internacionais celebrados por governos não-centrais. Brasília: MRE, 2002. p. 8. (XVIL Curso de Altos Estudos).

${ }^{22}$ PRIETO, Noé Cornago. O outro lado do novo regionalismo pós-soviético e da ásia-pacífico. In: VIGEVANI, Tullo (Org.). A dimensão subnacional e as relações internacionais. São Paulo: Unesp, 2004, p. $252-252$.
} 
exemplo de estratégia internacional levada a cabo por um Estado federal teve à frente o governador Pedro Simon, do Rio Grande do Sul, que no ano de 1987, criou a Secretaria Especial para Assuntos Internacionais, concebida pelo professor Ricardo Seitenfus. ${ }^{23}$

A Constituição da República de 1988, como já restou demonstrado, não institucionalizou, definitivamente, a paradiplomacia no ordenamento jurídico pátrio. Toda a competência internacional é atribuída à União. No entanto, o pacto federativo previsto na Carta Política criou algumas condições institucionais propícias para que os municípios e os estados federados pudessem se engajar em atividades paradiplomáticas. De fato, os entes federativos brasileiros não poderiam ficar à margem do processo, notadamente em razão da proliferação da paradiplomacia em países vizinhos, como, por exemplo, na Argentina.

Os problemas estruturais que propiciam o desenvolvimento da paradiplomacia no Brasil existem e são muitos. Dentre eles, um sistema federativo que concentra recursos no governo federal e cria dificuldades imensas até mesmo para a sobrevivência dos municípios e estados. Padecem os entes federados, sob o pálio de um regime tributário e fiscal inadequado, fortemente centralizador de receitas. Há que se levar em conta, ainda, a chamada "guerra fiscal", que lança em conflito os entes federados, ansiosos em amealharem mais receitas. Gilberto Marcos Antônio Rodrigues ressalta que outra fonte de grande conflito entre a União, os estados federados e os municípios tem sido a Lei de Responsabilidade Fiscal (Lei Complementar n. 101, de 04.05.2000), que impede que os governos subnacionais gastem mais do que o permitido em razão da sua capacidade de arrecadação, algo que embora possa ser um importante instrumento de ajuste fiscal, colocam em descoberto os problemas relacionados à autonomia financeira dos estados e municípios em relação à União. ${ }^{24}$

Apesar de todas as restrições à atuação paradiplomática no ordenamento jurídico brasileiro, os entes subnacionais têm demonstrado certa capacidade para atuar internacionalmente. Nada obstante, embora a prática da paradiplomacia encontre-se amplamente disseminada no território nacional, não há uma homogeneidade na forma de condução do assunto pelos estados federados. Em verdade, o que existe é uma certa dispersão em termos de suas diferentes formas de estrutura e de organização. Como não se trata de uma matéria institucionalizada, não há um modelo a ser seguido pelos entes federados, razão pela qual, dependendo dos interesses de cada região, do perfil político do estado e até mesmo do

\footnotetext{
${ }^{23}$ RODRIGUES, Gilberto Marcos Antônio. Globalización y gobiernos subnacionales en Brasil. Vetas: Revista de El Colegio San Luis, San Luis Potosí, año IV, n. 11, p. 57, mayo/ago. 2002.

${ }^{24}$ RODRIGUES, Gilberto Marcos Antônio. Globalización y gobiernos subnacionales en Brasil. Vetas: Revista de El Colegio San Luis, San Luis Potosí, año IV, n. 11, p. 57, mayo/ago. 2002, p. 56-57.
} 
partido político que se encontra no poder, há diferentes enfoques e estruturas em sua área de atuação. Com efeito, há estruturas governamentais de estados em formas de Secretarias, Subsecretarias, Assessorias, Coordenadorias, bem como órgãos integrantes de estruturas voltadas ao comércio exterior ou internacional.

Atualmente encontra-se em tramitação no Congresso Nacional, mais especificamente, no Senado Federal, o Projeto de Lei do Senado n. 98, de 2006, de Autoria do Senador Antero Paes de Barros, que dispõe sobre a aplicação de normas internacionais no Brasil e dá outras providências. ${ }^{25}$

Trata-se de proposta legislativa fruto de um trabalho desenvolvido pelos Professores Paulo Caliendo e Valério de Oliveira Mazzuoli, que busca fixar regras relativas à integração, eficácia e aplicabilidade dos tratados no Brasil. Os autores da proposta legislativa, ressaltando a divergência tanto doutrinária, quanto jurisprudencial em relação a vários pontos da aplicação dos tratados no ordenamento jurídico brasileiro, advertem sobre a necessidade preemente de sistematizar não só a aplicação dos tratados no Brasil, como cuidar de outros assuntos conexos à matéria.

O Senador Arthur Virgílio opinou pela aprovação do PLS n. ${ }^{\circ}$ 98/2006, nos termos de um substitutivo apresentado, onde há uma série de considerações quanto a aspectos de técnica legislativa e de mérito.

Embora o texto apresentado possa não vir a agradar os defensores mais árduos da paradiplomacia, haja vista destinar aos entes não centrais apenas a prática de "convênios internacionais", é inegável que se trata de um avanço considerável na inserção internacional dos entes federados no ordenamento jurídico brasileiro.

Além da proposta legislativa acima colacionada, com o objetivo de dar base institucional, potencializar e dar maior capilaridade às ações internacionais no país, abrindo novos nichos de oportunidade para o desenvolvimento econômico e social da federação, o Deputado Federal André Costa (PDT/RJ) apresentou ao Congresso Nacional a Proposta de Emenda à Constituição (PEC) 475/2005, a chamada "PEC da Paradiplomacia", que acrescenta parágrafo ao artigo 23 da Constituição da República, para permitir que estados federados, Distrito Federal e municípios possam promover atos e celebrar acordos ou convênios com

\footnotetext{
${ }^{25}$ Atualmente, o projeto encontra-se desde 27.12.2006 na Comissão de Relações Exteriores e Defesa Nacional, aguardando designação do relator. Ressalte-se que no dia 19.07.2006, o Senador Artur Virgílio apresentou parecer favorável, na forma do substitutivo apresentado.
} 
entes subnacionais estrangeiros. ${ }^{26}$ Nada obstante, tal proposta não vingou, nos termos do Parecer do Relator, que opinou pela sua inadmissibilidade.

Se a primeira proposta de regulamentação da incorporação dos tratados no ordenamento jurídico brasileiro, aqui citada, pecou pela falta de ousadia por ter perdido a oportunidade de dar legitimidade ou até mesmo proibir expressamente a paradiplomacia, a segunda proposta, de emenda constitucional tratando especificamente da matéria, não foi analisada da maneira devida pela Comissão de Constituição e Justiça e de Cidadania da Câmara dos Deputados. Mais uma oportunidade acabou "passando em branco" e o fenômeno da paradiplomacia continua sendo conduzido e crescendo, à margem de uma estrita legalidade.

Ainda em se tratando de proposta de emenda constitucional, interessante ressaltar que José Vicente da Silva Lessa entende que a possibilidade de delegar capacidade de firmar atos internacionais às unidades federadas, mediante eventual emenda constitucional poderia encontrar dificuldades doutrinárias intransponíveis. ${ }^{27}$ Nessa mesma linha de idéias, Tatiana Prazeres argumenta que, sendo a federação um núcleo material irredutível da Constituição da República, e uma vez que a atuação externa do Estado é um dos principais elementos que caracterizam a federação, a ação paradiplomática "estaria solapando as bases do federalismo e instituindo, ainda que subrepticiamente, a confederação." 28 Ambos os autores entendem que um projeto de emenda constitucional que propusesse a extensão aos estados da capacidade de celebrar tratados, conspiraria contra a forma federativa do Estado brasileiro, e não poderia sequer ser objeto de deliberação, haja vista o estabelecido no artigo 60, parágrafo $4^{\mathrm{o}}$, inciso I, da Constituição da República.

Em que pese todo o renome dos citados autores, tal posicionamento deve ser entendido com as devidas ressalvas, sob pena de se transformar em um equívoco. Pode-se entender, sem sombra de dúvidas, que uma proposta de emenda constitucional com esse conteúdo, ao invés de ser tendente a enfraquecer a federação brasileira, voltar-se-ia, isso sim, a fortalecê-la, na medida em que fortaleceria a atuação dos governos não centrais voltados para políticas locais e regionais dirigidas à realização da competência material comum

\footnotetext{
${ }^{26}$ Apesar de todo o esforço do parlamentar, no dia 18 de abril de 2006, em sede de Comissão de Constituição e Justiça e de Cidadania da Câmara dos Deputados, parecer do Relator Deputado Ney Lopes (PFL/RN) opinou pela inadmissibilidade da proposta.

${ }^{27}$ LESSA, José Vicente da Silva. A paradiplomacia e os aspectos legais dos compromissos internacionais celebrados por governos não-centrais. Brasília: MRE, 2002. p. 99. (XVIL Curso de Altos Estudos).

${ }^{28}$ PRAZERES, Tatiana Lacerda. Federalismo e relações internacionais: a atuação dos estados brasileiros no âmbito externo. São José, 2000. Dissertação (Mestrado)-Universidade de São José. 2000. p. 105.
} 
estabelecida na própria Constituição da República. Além disso, poderia compreender-se que tal proposta normativa estaria em completa consonância com o princípio da subsidiariedade, que democratiza e fortalece a expansão do poder ascendente.

Ainda assim, pode-se concluir que a falta da institucionalização da paradiplomacia no ordenamento jurídico brasileiro não inibe, por completo, a atuação internacional dos entes subnacionais. Para José Vicente da Silva Lessa, há exemplos de iniciativa estadual plenamente amparada pelos requisitos constitucionais para a celebração de tratados. $\mathrm{O}$ autor menciona, além do Protocolo n. 23 (Regional Fronteiriço) do Programa de Integração e Cooperação Econômica entre o Brasil e a Argentina, sob cuja égide se processa a interação CODESUL/CRECENEA, seguido do Ajuste Complementar ao Acordo de Cooperação Científica e Tecnológica entre o Governo da República da Argentina sobre Atividades de Cooperação entre o Estado do Rio Grande do Sul e a Secretaria de Ciência e Tecnologia da Presidência da Nação Argentina; o Memorando de Entendimento entre o Governo da República Federativa do Brasil e a Organização das Nações Unidas para Apoio a Atividades de Cooperação e de Intercâmbio em Administração Pública, de 6 de julho de 2001, com vistas à implementação de atividades do Centro Internacional de Inovação e Intercâmbio em Administração Pública da Fundação Luís Eduardo Magalhães, na Bahia. ${ }^{29}$

Pelo primeiro instrumento, acima citado, que visava o desenvolvimento de projetos tecnológicos, o Governo brasileiro conferiu ao estado do Rio Grande do Sul, por intermédio de sua Secretaria de Ciência e Tecnologia, a coordenação brasileira do Ajuste, enquanto que o Governo Argentino conferia à Secretaria de Ciência e Tecnologia da Presidência a mesma capacidade. A segunda avença, que buscava a implementação de um Centro Internacional de Inovação e Intercâmbio em Administração Pública, foi assinada em 16 de novembro de 2001 em Nova York pelo Governo Federal, pelo Governo da Bahia e pelo UNDESA (Departamento de Assuntos Econômicos e Sociais das Nações Unidas).

$\mathrm{Na}$ doutrina internacional, há vários autores que creditam a possibilidade de celebração de atos internacionais por entes subnacionais naquilo que se entende por "tratados-marco". Tais tratados, subscritos por órgãos centrais dos entes centrais, e cujas matérias dizem respeito às mais diversas matérias, outorgam proteção normativa aos atos posteriormente celebrados pelas entidades subnacionais, tendo por baixo a garantia dos Estados - parte.

\footnotetext{
${ }^{29}$ LESSA, José Vicente da Silva. A paradiplomacia e os aspectos legais dos compromissos internacionais celebrados por governos não-centrais. Brasília: MRE, 2002. p. 90-91. (XVIL Curso de Altos Estudos).
} 
Os dois exemplos citados, celebrados sob os auspícios dos chamados tratadosmarco, demonstram que a atuação externa dos entes subnacionais pode se desenvolver dentro de um marco constitucional e conformar instrumentos normativos efetivos, mediante a celebração de atos entre pessoas de Direito Internacional Público, legalmente habilitadas para tanto. Em outras palavras, conclui-se que mesmo sem uma forma institucionalizada de paradiplomacia no ordenamento jurídico brasileiro, ainda assim, podem as unidades federadas concluir entendimentos formais com unidades ou governos estrangeiros se o ato resultante for celebrado pelo Governo federal com o governo central do outro Estado.

No entanto, há que se ter em mente que o uso dos chamados tratados-marco, conhecidos também como tratados-quadro ou "acordos guarda-chuva" deve ser limitado, e não indiscriminado. De fato, um acordo básico não deve existir para dar "cobertura" a um sem-número de iniciativas setoriais desvinculadas da intenção das partes contratantes. Reside aí a limitação da implementação da paradiplomacia pela via desse instituto.

\section{Conclusão}

O desenvolvimento das relações internacionais nas últimas décadas, motivado pelos mais diversos fatores, acarretou marcantes modificações nos campos políticos, econômicos e jurídicos dos relacionamentos intra-estatais. A participação dos entes não centrais no processo de globalização, principalmente com a criação de blocos regionais, não pode mais ser desprezado. Verifica-se, em verdade, um processo irreversível de participação dos governos locais e regionais no cenário internacional.

Nada obstante, o crescimento dessa participação não foi acompanhado do necessário respaldo jurídico. De fato, salvo raras exceções, a inserção internacional dos entes não centrais na política exterior vem sendo levada a cabo sob uma aparente ilegalidade, haja vista a falta de previsão normativa para tanto, o que gera uma inegável insegurança jurídica.

A existência de alguns modelos institucionalizados de paradiplomacia reforça a idéia de que a inserção internacional dos entes subnacionais já é uma realidade que não pode ser deixada à margem da legalidade. Faz-se imperioso ressaltar, inclusive, que alguns estados federados de países desenvolvidos possuem economia e relações comerciais muito mais expressivas que vários Estados soberanos, e a inserção internacional desses entes não pode ser ignorada. 
No ordenamento jurídico pátrio, especificamente, tal omissão legislativa pode ser superada, ainda que de forma não inteiramente satisfatória, com a aprovação do Projeto de Lei Complementar n. ${ }^{\circ} 98$, de 2006, que dispõe sobre a aplicação de normas internacionais no Brasil e dá outras providências.

De fato, as regras e os princípios insculpidos no projeto normativo em tela refletem alguns dos modernos posicionamentos da doutrina sobre a matéria, haja vista a previsão expressa da possibilidade de inserção internacional de estados membros e municípios através dos convênios internacionais.

Enquanto ainda não há uma institucionalização expressa da paradiplomacia brasileira, a existência de alguns tratados-marco conferem certa legitimidade à inserção internacional dos entes não centrais. De fato, tais instrumentos, subscritos por órgãos centrais dos entes centrais, outorgam proteção normativa aos atos posteriormente celebrados pelas entidades subnacionais, e demonstram que a atuação externa dos entes subnacionais pode se desenvolver dentro de um marco constitucional e conformar instrumentos normativos efetivos, mediante a celebração de atos entre pessoas de Direito Internacional Público, legalmente habilitadas para tanto.

Conclui-se, portanto, que mesmo sem uma forma institucionalizada de paradiplomacia no ordenamento jurídico brasileiro, ainda assim, podem as unidades federadas concluir entendimentos formais com unidades ou governos estrangeiros se o ato resultante for celebrado pelo Governo federal com o governo central do outro Estado.

Enfim, somente o tempo dirá se uma futura institucionalização da paradiplomacia no ordenamento jurídico brasileiro, da forma como proposta, irá atender realmente aos anseios dos entes não centrais, propiciando sua inserção internacional, e, ao mesmo tempo, respeitando o pacto federativo.

Artigo recebido em março de 2007.

Aceito para publicação em abril de 2007.

\section{Referências}

ACCIOLY, Hildebrando. Tratado de direito internacional público. 2.ed. Rio de Janeiro: Ministério das Relações Exteriores, 1956.

BEVILÁQUA, Clóvis. Direito público internacional. 2. ed. Rio de Janeiro: F. Bastos, 1939. 
BRASIL. Câmara dos Deputados. Diário da Câmara dos Deputados. Brasília, 08 dez. 1995. p. 3386. col. 01.

BRASIL. Supremo Tribunal Federal. Carta Rogatória n. ${ }^{\circ}$ 8.279, da República Argentina, de 04 de maio de 1998. Rel. Min. Celso de Mello. Julgada em 17 jun. 1998. Diário da Justiça da União, Brasília, 10 ago. 2000. p. 34.

GRUBISA, Damir. Paradiplomacy in action: the foreign relations of subnational governments. London: Mediterranean Politics, 1999.

LECOURS, André. Paradiplomacy: reflections on the foreign policy and international relations of regions. International Negotiation. [S.1.], n. 7, p. 92, 2002.

LESSA, José Vicente da Silva. A paradiplomacia e os aspectos legais dos compromissos internacionais celebrados por governos não-centrais. Brasília: MRE, 2002. (XVIL Curso de Altos Estudos).

MAZZUOLI, Valério de Oliveira. Tratados internacionais. 2. ed. São Paulo: J. Oliveira, 2004.

MELO, Celso D. de Albuquerque. Curso de direito internacional público. 13. ed. Rio de Janeiro: Renovar, 2001.

PELET, Alain; DAILLIER, Patrick; DINH, Nguyen Quoc. Direito internacional público. 2. ed. Lisboa: Fundação Calouste Gulbenkain, 2003.

PRAZERES, Tatiana Lacerda. Federalismo e relações internacionais: a atuação dos estados brasileiros no âmbito externo. São José, 2000. Dissertação (Mestrado)-Universidade de São José. 2000.

. Por uma atuação constitucionalmente viável das unidades federadas brasileira. In: VIGEVANI, Tullo (Org.). A dimensão subnacional e as reações internacionais. São Paulo: Unesp, 2004.

PRIETO, Noé Cornago. O outro lado do novo regionalismo pós-soviético e da ásia-pacífico. In: VIGEVANI, Tullo (Org.). A dimensão subnacional e as relações internacionais. São Paulo: Unesp, 2004.

REZEK, José Francisco. Direito dos tratados. Rio de Janeiro: Forense, 1984.

REZEK, José Francisco. Direito internacional público. 9. ed. São Paulo: Saraiva, 2002.

ROBERTSON, Roland. Globalização: teoria social e cultura global. Petrópolis: Vozes, 2000.

RODRIGUES, Gilberto Marcos Antônio. Globalización y gobiernos subnacionales en Brasil. Vetas: Revista de El Colegio San Luis, San Luis Potosí, año IV, n. 11, p. 57, mayo/ago. 2002.

ROSENAU, James. Patterned chaos in global life: structure and process in the two worlds of world politics. International Political Science Review, [S.1.], n. 9, p. 327, 1988. 
SILVA, Roberto Luiz. Direito internacional público. 2. ed. Belo Horizonte: Del Rey, 2005.

SORENSEN, Max. Manual de derecho internacional público. México: Fondo de Cultura Económica, 1998.

VON LISZT, Franz. Derecho internacional público. Barcelona: Gustavo, 1929. 


\section{Resumo}

$\mathrm{O}$ artigo ora apresentado tem por objeto o estudo da inserção internacional dos entes subnacionais no cenário da política externa através do instituto chamado paradiplomacia. $\mathrm{O}$ silêncio normativo ainda existente na maioria dos ordenamentos jurídicos, a existência de propostas legislativas para a institucionalização da paradiplomacia no Brasil, a incipiente doutrina, bem como os poucos exemplos de inserção internacional de entes não centrais, tornam propício o desenvolvimento do trabalho. Por fim, esclareça-se que há a preocupação em não tornar a inserção internacional dos entes subnacionais como um instrumento de política secessionista, ou mesmo em um mecanismo que possa gerar qualquer ofensa ao pacto federativo, previsto na Constituição da República de 1988.

Palavras-chave: Direito das Relações Internacionais. Tratados. Capacidade de Celebrar Tratados. Federalismo. Paradiplomacia.

\section{Abstract}

This article focuses on study of the international insertion of sub-national entities in the foreign political scenario through paradiplomacy. The normative silence still existent in the majority of juridical rulings; the existence of legislative proposals to the institutionalization of the paradiplomacy in Brazil; the incipient doctrine, as well as the many examples of international insertion of non-central entities, enable the development of the present work. Finally, it is important to notice that there has been much preoccupation not to make the international insertion of sub-national entities, an instrument of separatism, or even a mechanism that could be contrary to the Federative accord, foreseen in the 1988 Constitution.

Keywords: Public International Law. Treaties. Treaty-making capacity. Federalism. Paradiplomacy. 